University of Nebraska - Lincoln

DigitalCommons@University of Nebraska - Lincoln

May 1991

\title{
RBE VS. DOSE FOR LOW DOSES OF HIGH-LET RADIATIONS
}

Robert Katz

University of Nebraska-Lincoln, rkatz2@unl.edu

F. A. Cucinotta

NASA Langley Research Center, Hampton, VA, francis.cucinotta@unlv.edu

Follow this and additional works at: https://digitalcommons.unl.edu/physicskatz

Part of the Physics Commons

Katz, Robert and Cucinotta, F. A., "RBE VS. DOSE FOR LOW DOSES OF HIGH-LET RADIATIONS" (1991). Robert Katz Publications. 30.

https://digitalcommons.unl.edu/physicskatz/30

This Article is brought to you for free and open access by the Research Papers in Physics and Astronomy at DigitalCommons@University of Nebraska - Lincoln. It has been accepted for inclusion in Robert Katz Publications by an authorized administrator of DigitalCommons@University of Nebraska - Lincoln. 


\title{
RBE VS. DOSE FOR LOW DOSES OF HIGH-LET RADIATIONS
}

\author{
Robert Katz \\ University of Nebraska, Lincoln, NE 68588-0111 \\ and \\ F. A. Cucinotta \\ NASA Langley Research Center, Hampton, VA 23665-5225
}

\begin{abstract}
According to track theory, the relative biological effectiveness (RBE) of high linear energy transfer (LET) radiations varies with cellular radiosensitivity parameters and the radiation environment. Of special interest is that the RBE varies as the dose of high-LET radiation to the power $(1 / m-1)$ where $m$ is the "target number" parameter, which varies from $2-4$ in different cell lines. This applies to neutrons as well as to heavy ions at sufficiently low doses such that cells are not activated in the $\gamma$-kill mode; that is, the tracks of single heavy ions are sufficiently far apart so that there are few cases of inter-track inactivation.
\end{abstract}

\section{INTRODUCTION}

ACCORDING to track theory, the killed (or transformed) fraction of cells irradiated with a dose $D_{x}$ of x rays is:

$$
K_{x}=\left[1-\exp \left(D_{x} / E_{o}\right)\right]^{m},
$$

where $E_{o}$ and $m$ are two of the four cellular radiosensitivity parameters, the others being $\sigma_{o}$ and $\kappa$ (Katz et al. 1971). In track theory, the multi-target, single-hit per target formula of target theory is used to represent the response of cells to $\mathrm{x}$ or $\gamma$ rays.

Similarly, at low fluences where inter-track effects ( $\gamma$ kill) due to $\delta$ rays from adjacent ions may be neglected, the killed fraction of cells from a fluence $F$ of ions is:

$$
K_{i}=1-\exp (-\sigma F) \text {. }
$$

Expanding both exponentials and retaining only the lowest order terms, we have:

$$
K_{x}=\left(D_{x} / E_{\omega}\right)^{m}
$$

and

$$
K_{i}=\sigma F=\sigma D_{i} / L,
$$

where $D_{i}$ is the dose of high linear energy transfer (LET) radiation and $L$ is the LET or stopping power. Noting that

relative biological effectiveness $(\mathrm{RBE})=\left(D_{x}\right) /\left(D_{i}\right)$

(Manuscript received 15 August 1990; revised manuscript received 21 September 1990, accepted 4 October 1990) at the same biological effect where $K_{x}=K_{i}$, we find:

$$
\mathrm{RBE}=\left(K_{i}\right)^{(1 / m-1)}\left(E_{o} \sigma / L\right) .
$$

Making use of eqn (4), we find

$$
\mathrm{RBE}=\left(D_{i}\right)^{(1 / m-1)}(\sigma / L)^{(1 / m)} E_{o} .
$$

When a cell sample is irradiated with neutrons, or with an arbitrary mixed radiation field, it is possible to find an equivalent irradiation (Katz et al. 1972, 1976) with a beam of (imaginary) monoenergetic ions whose charge, speed, and fluence yield the dose, and the ion kill and $\gamma$-kill dose fractions equal to the original field. In this case, the survival curves for the two irradiations are congruent. Thus, eqn (7) is applicable to irradiations with neutrons as well as to track segment irradiations with beams of heavy ions.

Among the several biological systems to which we have fit cellular radiosensitivity parameters, we have found cell lines for which $m$ varies from 2-4 (Roth et al. 1976; Katz 1988; Waligorski et al. 1987; Waligorski 1990). We would expect a plot of RBE vs. heavy ion (or neutron) dose to exhibit a variation with dose to the power $(1 / \mathrm{m}$ - 1) at doses low compared to $E_{o}$.

These conclusions differ from those drawn from the theory of dual radiation action (Kellerer et al. 1972), based on the assumption that the response of a cellular system to $\gamma$ rays is described by a linear-quadratic relation and that its response to neutrons is exponential, from which the RBE varies inversely with the square root of the neutron dose.

Our four-parameter model for cellular radiation effects has been applied to cell killing, mutagenesis, chromosome aberrations, and transformations where data exist 
for an adequate range in LET and dose. We would expect eqn (7) to be applicable to all of these. Even here there are few cases known to us where the dose data extend down to $0.01 \mathrm{~Gy}$. We have not been able to apply this model to carcinogenesis for lack of data of adequate dynamic range in dose and in LET. Additionally, experiments in which cancers are induced typically do not state the number of cells at risk or the number of cancers induced. These data are essential to the application of our model.

\section{COMPARISON OF THEORY WITH EXPERIMENT}

A recent study of the survival of C3H10T $\frac{1}{2}$ cells by Bettega et al. (1990) is of particular interest here. The survival of these cells was measured at doses down to 0.01 Gy after irradiation with $31-\mathrm{MeV}$ protons $($ LET $=1.83$ $\mathrm{keV} / \mu \mathrm{m}$ ) and 4.3-MeV $\alpha$ particles (LET $=101 \mathrm{keV} /$ $\mu \mathrm{m})$. For calculations of the RBE, protons were taken as surrogate for $\mathrm{x}$ rays. The cell survival after proton irradiation is well represented by a multi-target formula [eqn (1)] for which $E_{o}=2.0 \pm 0.1 \mathrm{~Gy}$ and $m=3.3 \pm 0.5$. For $\alpha$-particle irradiation, $E_{o}=0.61 \pm 0.02 \mathrm{~Gy}$ and $m=1$. These authors display a plot of RBE vs. dose in which RBE $\propto D_{i}^{-0.61}$ for $\alpha$-particle doses between 0.01 and 0.1 Gy. At the lower limit of experimental uncertainty in $m$ we would expect RBE $\propto D_{i}^{-0.64}$ from eqn (7). At a dose of $0.01 \mathrm{~Gy}$, the mean separation of $\alpha$ particles is $40 \mu \mathrm{m}$, fulfilling the condition of our derivation that the incident ions are sufficiently far apart that $\gamma$ kill may be neglected.

It is interesting to compare the parameters for sur- vival of these cells after low-LET irradiation as measured here with parameters inferred from measurement of their survival after bombardment with a series of low- and highLET irradiations at higher doses. Thus, parameters reported by Waligorski (1990) where references as fitted visually to the survival data of Yang are $E_{o}=1.7 \mathrm{~Gy}$ and $m=3.0$, while parameters fitted by use of a computer minimizing program to the data of Hei are $E_{o}=1.46 \mathrm{~Gy}$ and $m=3.3$. (Yang and Hei are references reported in Waligorski 1990.) The agreement of $m$ here inferred from heavy-ion data and from direct measurement is striking.

\section{CONCLUSION}

Track theory is based on the premise that the response of cells to high-LET radiations is a geometric transform of their response to low-LET radiations through the radial distribution of dose from $\delta$ rays. In the event that the difference in irradiation times from $\gamma$ rays and the $\delta$ rays from a passing ion may be neglected, the radiosensitivity parameters deduced from a series of highLET survival experiments at high doses should be consistent with the survival after $\gamma$ irradiation and should predict the low-dose response for both $\gamma$ rays and heavy ions. In the present instance, we approach that consistency.

Acknowledgment-This work is supported by the United States Department of Energy and the National Aeronautics and Space Administration.

\section{REFERENCES}

Bettega, D.; Calzolari, P.; Ottolenghi, A.; Tallone Lombardi, L. Oncogenic transformation induced by high and low LET radiations. Radiat. Prot. Dosim. 31:279-283; 1990.

Katz, R. Radiobiological modeling based on track structure. In: Kiefer, J., ed. Quantitative mathematical methods in radiation biology. Berlin: Springer-Verlag; 1988.

Katz, R.; Ackerson, B.; Homayoonfar, M.; Sharma, S. C. Inactivation of cells by heary ion bombardment. Radiat. Res. 47:402-405; 1971 .

Katz, R.; Fullerton, B. G.; Roth, R. A.; Sharma, S. C. Simplified RBE-dose calculations for mixed radiation fields. Health Phys. 30:148-150; 1976.
Katz, R.; Sharma, S. C.; Homayoonfar, M. Irradiation equivalence. Health Phys. 23:740-742; 1972.

Kellerer, A. M.; Rossi, H. H. The theory of dual radiation action. Curr. Top. Radiat. Res. Q. 8:85-158; 1972.

Roth, R. A.; Sharma, S. C.; Katz, R. Systematic evaluation of cellular radiosensitivity parameters. Phys. Med. Biol. 21:491503; 1976.

Waligorski, M. P. R. Radiosensitivity parameters for cancer-like biological endpoints in some mammalian cell cultures. Radiat. Prot. Dosim. 31:299-302; 1990.

Waligorski, M. P. R.; Sinclair, G. L.; Katz, R. Radiosensitivity parameters for neoplastic transformations in C3H 10T $\frac{1}{2}$ cells. Radiat. Res. 111:424-437; 1987. 